\title{
Weight Status and Self-Perception of Weight Among Women of Childbearing Age - China, 2015
}

\author{
Hongyun Fang'; Qiya Guo'; Lahong Ju'; Shujuan $\mathrm{Li}^{1}$; Xiaoli Xu' ${ }^{1}$; Wei Piao'; Dongmei $\mathrm{Yu}^{1}$; Liyun Zhao ${ }^{1, *}$
}

\section{Summary \\ What is already known about this topic? \\ Both lean and obese women carry a risk for adverse pregnancy outcomes. Correct self-perception of body weight status is necessary for optimal weight control. \\ What is added by this report? \\ Data from the Nutrition and Chronic Disease Surveillance of Chinese Residents in 2015 were used in this study. The weight status and self-perception of weight among women of childbearing age in China were analyzed to provide basic data for improving the nutritional health of women of childbearing age. \\ What are the implications for public health practice? \\ Around $45 \%$ of women of childbearing age misperceive their body weight status. Future actions to improve body weight perception in women of childbearing age are necessary to increase the impact of public health campaigns focusing on a healthy body weight.}

In the United Nations population statistics, women of childbearing age were defined as being between 15-49 years old. According to the data of the Sixth Census in 2010, the total number of women who were aged 15-49 years in China was about 380 million. Childbearing is important and it is thus important to identify factors that may influence the ability to give birth to children. Beyond age, several lifestyle-related factors, such as excess body weight, obesity, underweight, smoking, intense sporting activity, alcohol consumption, drug addiction, or abuse of other substances, have an adverse influence on female fertility (1-3). Accuracy of body weight perception is an individual's perception of their body weight in comparison with actual body weight, and a correct selfperception of body weight status is necessary for optimal weight control. In this report, we aimed to analyze the weight status and self-perception of weight among women of childbearing age in China. The data were obtained from the China National Chronic Diseases and Nutrition Surveillance of Adults (2015).
The proportion of normal weight and underweight in women of childbearing age were $54.3 \%$ and $5.7 \%$ respectively, and the incidence of normal weight and underweight was the highest in the group aged 18-24 years; the rate of overweight and obesity were $28.3 \%$ and $11.7 \%$, respectively, and the proportion of overweight and obesity was highest in the group aged 35-49 years. Only 55.6\% of women of childbearing age perceived their body weight correctly. Correct evaluation of one's own weight is necessary for taking weight control measures for healthy weight management. Actions should be taken to improve the cognitive level of weight of women of childbearing age to guide them to correctly manage their own weight.

China National Chronic Diseases and Nutrition Surveillance of Adults was a descriptive and crosssectional study conducted in 2015 (4). Demographic information, perception of body weight, anthropometric measures [weight, height, and body mass index (BMI)] were assessed. Trained investigators using standardized protocols measured height and weight using standardized equipment. Height was measured with a height meter (TZG type) with a minimum scale of $0.1 \mathrm{~cm}$; weight was measured with an electronic scale (Tanita HD-390) with a minimum scale of $0.1 \mathrm{~kg}$. A total of 43,077 women of childbearing age were included in this study, including 17,782 urban women and 25,295 rural women. Each participant was asked to rate her own body weight category as underweight, normal weight, overweight, or obese before anthropometric measurement. We calculated BMI from measured weight and height, and the women were categorized into 4 groups according to their BMI as follows (according to the Criteria of Weight for Adults of the health industry standard of China, WS/T 428-2013):

Underweight: BMI $<18.5 \mathrm{~kg} / \mathrm{m}^{2}$

Normal: $18.5 \leq \mathrm{BMI}<24.0 \mathrm{~kg} / \mathrm{m}^{2}$

Overweight: $24 \leq$ BMI $<28.0 \mathrm{~kg} / \mathrm{m}^{2}$

Obese: $\mathrm{BMI} \geq 28.0 \mathrm{~kg} / \mathrm{m}^{2}$

Weighted coefficients accommodated the sampling scheme for unequal probabilities of sample selection 
and the post-stratification weights, which harmonized the sample structure of the surveillance with that of the Sixth National Population Census in 2010 (5). Prevalence by region (urban and rural), and age were estimated. SAS software (version 9.4, SAS Institute Inc., Cary, USA) was applied for statistical analysis.

General characteristics of the sample are shown in Table 1 . We investigated women of childbearing age from urban $(41.3 \%)$ and rural $(58.7 \%)$ areas in China and considered 3 age groups: $18-24$ years $(7.4 \%)$, $25-34$ years $(26.7 \%)$ and $35-49$ years $(65.9 \%)$. The mean BMI of Chinese childbearing age women was $23.6 \mathrm{~kg} / \mathrm{m}^{2}\left(23.3 \mathrm{~kg} / \mathrm{m}^{2}\right.$ in urban areas and $23.8 \mathrm{~kg} / \mathrm{m}^{2}$ in rural areas) and increased with the age. Based on objective body weight status, $5.7 \%$ were classified as underweight, $54.3 \%$ were normal weight, $28.3 \%$ were overweight, and $11.7 \%$ were obese. The prevalence of underweight decreased with age and was $12.5 \%$ among women 18-24 years of age. The prevalence of overweight increased proportionally with increasing age as the groups aged 18-24, 25-34, and 35-49 had rates of $17.1 \%, 22.9 \%$, and $36.3 \%$, respectively. Similarly, the obese prevalence of women also increased with age, and the prevalence of obese women aged 18-24, 25-34, and 35-49 years were 7.6\%, $10.2 \%$, and $14.3 \%$. Within each age group, women residing in rural areas were more likely to be overweight and obese than those in urban areas.

Table 2 shows the consistency of BMI and body weight perception of Chinese women at childbearing age in 2015. Among normal weight women, 28.1\% underestimated or overestimated their weight, $8.6 \%$ thought they were low weight and $19.5 \%$ thought they were overweight or obese. Among underweight women, $55.7 \%$ perceived their body weight heavier than their actual body weight, in which $2.1 \%$ perceived themselves as overweight or obese. Among overweight and obese women, $42.5 \%$ perceived their body weight lighter than their actual body weight, in which $1.9 \%$ perceived themselves as underweight.

Table 3 provides the association of BMI and body weight perception. Both permutations were divided into 3 groups: consistency, underestimation, and overestimation; $55.6 \%$ women of childbearing age accurately perceived their weight status, $15.8 \%$ underestimated their weight status, and $28.6 \%$ overestimated their weight status. Women in urban areas were less likely to overestimate their weight than those in rural areas. Women aged 35-49 years were the most likely to overestimate their weight (37.2\%), while young women aged $18-24$ years were more likely than other ages to underestimate their weight $(24.7 \%)$.

\section{DISCUSSION}

Weight status and BMI are important indicators reflecting the physical health status of women of childbearing age. In our study, the proportion of underweight, normal weight, overweight and obese among Chinese women of childbearing age in 2015 were $5.7 \%, 54.3 \%, 28.3 \%$, and $11.7 \%$, respectively. Young women aged 18-24 years had a higher incidence of underweight (12.5\%), especially in urban young women (15.6\%), while the incidence of overweight and obese increased with age. Nearly half of women of childbearing age in China were abnormal

TABLE 1. Descriptive characteristics and body mass index (BMI) category of Chinese women of childbearing age, 2015.

\begin{tabular}{|c|c|c|c|c|c|c|c|}
\hline \multirow{2}{*}{ Area type } & \multirow{2}{*}{ Age (years) } & \multirow{2}{*}{$\mathbf{N}(\%)$} & \multirow{2}{*}{ BMI $\left(\mathrm{kg} / \mathrm{m}^{2}\right.$, Mean, SE) } & \multicolumn{4}{|c|}{ BMI category $(\%, 95 \% \mathrm{Cl})$} \\
\hline & & & & Underweight & Normal & Overweight & Obese \\
\hline \multirow{4}{*}{ Urban } & $18-24$ & $1,288(7.2)$ & $21.9(0.13)$ & $15.6(12.8,18.4)$ & $64.0(60.3,67.6)$ & $13.5(10.1,16.8)$ & $7.0(4.8,9.1)$ \\
\hline & $25-34$ & $5,130(28.9)$ & $22.9(0.11)$ & $7.6(6.4,8.9)$ & $61.7(59.4,64.1)$ & $21.0(18.9,23.2)$ & $9.6(8.0,11.2)$ \\
\hline & $35-49$ & $11,364(63.9)$ & $24.3(0.06)$ & $1.7(1.3,2.0)$ & $50.3(48.5,52.1)$ & $34.9(33.2,36.7)$ & $13.1(11.9,14.3)$ \\
\hline & Subtotal & $17,782(41.3)$ & $23.3(0.07)$ & $6.5(5.7,7.4)$ & $56.7(55.2,58.2)$ & $26.1(24.7,27.5)$ & $10.7(9.8,11.6)$ \\
\hline \multirow{4}{*}{ Rural } & $18-24$ & $1,894(7.5)$ & $22.7(0.16)$ & $8.9(7.1,10.6)$ & $61.3(57.9,64.7)$ & $21.4(18.0,24.8)$ & $8.4(6.2,10.6)$ \\
\hline & $25-34$ & $6,358(25.1)$ & $23.3(0.09)$ & $6.7(5.7,7.6)$ & $56.7(54.9,58.6)$ & $25.5(23.8,27.1)$ & $11.1(9.7,12.5)$ \\
\hline & $35-49$ & $17,043(67.4)$ & $24.5(0.05)$ & $1.9(1.6,2.3)$ & $44.9(43.5,46.2)$ & $37.7(36.5,38.9)$ & $15.5(14.3,16.7)$ \\
\hline & Subtotal & $25,295(58.7)$ & $23.8(0.06)$ & $4.7(4.2,5.2)$ & $51.5(50.3,52.7)$ & $31.0(29.9,32.1)$ & $12.8(11.9,13.7)$ \\
\hline \multirow{4}{*}{ Total } & $18-24$ & $3,182(7.4)$ & $22.3(0.11)$ & $12.5(10.7,14.3)$ & $62.7(60.2,65.3)$ & $17.1(14.6,19.7)$ & $7.6(6.1,9.2)$ \\
\hline & $25-34$ & $11,488(26.7)$ & $23.0(0.08)$ & $7.2(6.4,8.0)$ & $59.6(58.0,61.2)$ & $22.9(21.5,24.4)$ & $10.2(9.2,11.3)$ \\
\hline & $35-49$ & $28,407(65.9)$ & $24.4(0.04)$ & $1.8(1.6,2.0)$ & $47.7(46.6,48.8)$ & $36.3(35.2,37.3)$ & $14.3(13.4,15.1)$ \\
\hline & Subtotal & $43,077(100.0)$ & $23.6(0.05)$ & $5.7(5.2,6.2)$ & $54.3(53.3,55.3)$ & $28.3(27.4,29.3)$ & $11.7(11.0,12.3)$ \\
\hline
\end{tabular}


TABLE 2. Consistency analysis of body mass index (BMI) and body weight perception of Chinese women of childbearing age, 2015.

\begin{tabular}{ccccc}
\hline \multirow{2}{*}{ BMI category } & \multirow{2}{*}{ Age (years) } & \multicolumn{3}{c}{ Body weight perception category (\%, 95\%Cl) } \\
\cline { 3 - 5 } & $18-24$ & Underweight (\%, 95\%Cl) & Normal (\%, 95\%Cl) & Overweight/obese (\%, 95\%Cl) \\
\hline \multirow{2}{*}{ Underweight } & $25-34$ & $47.4(42.8,52.1)$ & $57.1(46.3,67.9)$ & $2.1(0.7,3.5)$ \\
& $35-49$ & $48.0(41.3,54.7)$ & $49.8(45.0,54.5)$ & $2.8(0.9,4.7)$ \\
& Subtotal & $44.3(38.5,50.2)$ & $53.3(47.6,59.0)$ & $2.4(0.4,4.4)$ \\
& $18-24$ & $5.9(4.1,7.7)$ & $69.5(66.2,72.9)$ & $24.6(1.3,3.4)$ \\
Normal & $25-34$ & $6.5(5.7,7.4)$ & $71.5(69.5,73.4)$ & $22.0(20.1,23.9)$ \\
& $35-49$ & $11.5(10.3,12.7)$ & $73.5(71.9,75.2)$ & $14.9(13.7,16.1)$ \\
Overweight/Obese & $8.6(7.8,9.3)$ & $71.9(70.5,73.2)$ & $19.5(18.3,20.8)$ \\
& Subtotal & $1.4(0.4,2.5)$ & $35.2(29.7,40.8)$ & $63.3(57.7,69.0)$ \\
& $18-24$ & $1.2(0.8,1.7)$ & $34.8(32.1,37.5)$ & $64.0(61.3,66.7)$ \\
& $25-34$ & $2.3(1.9,2.7)$ & $44.0(42.1,45.9)$ & $53.7(51.8,55.7)$ \\
& $35-49$ & $1.9(1.6,2.3)$ & $40.6(38.9,42.4)$ & $57.4(55.7,59.2)$ \\
\hline
\end{tabular}

TABLE 3. Consistency of body mass index (BMI) and body weight perception by age and residence among Chinese women of childbearing age, 2015.

\begin{tabular}{lccc}
\hline Item & Consistent estimation $(\%, 95 \% \mathrm{Cl})$ & Underestimation $(\%, 95 \% \mathrm{Cl})$ & Overestimation $(\%, 95 \% \mathrm{Cl})$ \\
\hline Age (years) & $58.0(55.4,60.7)$ & $24.7(22.4,27.0)$ & $17.3(15.2,19.4)$ \\
$18-24$ & $59.1(57.6,60.6)$ & $18.9(17.3,20.4)$ & $22.0(20.6,23.5)$ \\
$25-34$ & $52.5(51.3,53.8)$ & $10.2(9.5,10.9)$ & $37.2(36.0,38.5)$ \\
$35-49$ & & & $24.2(22.6,25.8)$ \\
Area type & $57.4(56.1,58.7)$ & $18.4(17.2,19.6)$ & $33.7(32.6,34.9)$ \\
Urban & $53.5(52.3,54.7)$ & $12.8(11.9,13.7)$ & $28.6(27.5,29.7)$ \\
Rural & $55.6(54.7,56.5)$ & $15.8(15.0,16.6)$ & \\
Total & &
\end{tabular}

weight - i.e., they were underweight, overweight, or obese. Previous studies have shown that underweight, overweight, and obese may reduce fertility (1-3). Therefore, medical institutions and health education departments should take targeted measures to help women of childbearing age with abnormal weight improve their weight management.The accuracy of body weight perception refers to an individual's perception of their body weight (normal weight, underweight, overweight, or obese) compared with their actual body weight. Self-perception of body weight is influenced by many factors such as BMI, sex, age, race, ethnicity, and socioeconomic status $(6-8)$. Previous studies suggested that women tended to overestimate their weight status and men were more likely to underestimate $(7-8)$. However, there have been limited studies on the accuracy of body weight perception in women of childbearing age. The results of this study added to the literature by assessing the concept of accuracy of body weight perception in Chinese women of childbearing age based on nationally representative sample for the first time.

In our study, there was a significant difference between BMI and body weight perception in Chinese women of childbearing age. However, women with different BMIs have different self-perception tendencies. The current results showed that among normal weight women of childbearing age, $71.9 \%$ could correctly judge their body weight while $19.5 \%$ overestimated their weight and $8.6 \%$ underestimated. However, $55.7 \%$ of underweight women of childbearing age overestimated their body weight, and $42.5 \%$ of overweight and obese women of childbearing age underestimated their body weight. This result is similar to a previous study among US adults that obese and overweight persons tend to underestimate their body weight (9). The rate of false self-perception of body weight was high in women with abnormal BMI. 
In China, around $45 \%$ of Chinese women of childbearing age did not accurately rate their body weight status. Young women tended to underestimate their weight, while older women tended to overestimate their weight. This may be related to selfesteem or self-acceptance. Compared with other age groups, young women were less willing to admit that they were overweight, while older women were more receptive to the problem of becoming overweight. The rate of incorrectly perceiving weight $(45 \%)$ in our study was higher than Chinese American adults (32\%) (10). The accuracy of weight perception might be different in different ethnic and cultural backgrounds. A previous study reported that white women, even if they were of normal weight, were more likely to think they were overweight (6). Compared with Europeans, obese women in South Asia tend to underestimate themselves as normal weight (11).

The findings in this study are subject to at least two limitations. First, the method of self-assessment of body weight was used in this study, and the subjects rated their weight as underweight, normal, overweight and obese. This report didn't provide pictures of different body types for the respondents to choose. There are some differences in body shape judgment of underweight, normal, overweight and obese. Second, this is a cross-sectional study, this research couldn't track the impact of weight cognition on individual weight control and other health outcomes.

Both lean and obese women carry a risk for adverse pregnancy outcomes. Preventing abnormal body weight may improve women's reproductive health and save a portion of medical expenses for related treatment in China. Correct self-perception of body weight indicates that people have a correct understanding of their current weight status, which is necessary for weight control and prevention of weight related diseases. Our study showed a low agreement between self-perception of body weight status and objectively measured body weight status in women of childbearing age in China. Future actions to improve body weight perception in women of childbearing age are necessary.

Acknowledgments: Staff from local CDCs.

Funding: National Health Commission of the
People's Republic of China Medical Reform Major Program: China National Chronic Diseases and Nutrition Surveillance of Adults (2015).

doi: $10.46234 / \mathrm{ccdcw} 2021.056$

\# Corresponding author: Liyun Zhao, zhaoly@ninh.chinacdc.cn. ${ }^{1}$ National Institute for Nutrition and Health, Chinese Center for
Disease Control and Prevention, Beijing, China.

Submitted: December 31, 2020; Accepted: February 20, 2021

\section{REFERENCES}

1. Loret de Mola JR. Obesity and its relationship to infertility in men and women. Obstet Gynecol Clin North Am 2009;36(2):333-46. http://dx.doi.org/10.1016/j.ogc.2009.03.002.

2. Frisch RE. Body fat, menarche, fitness and fertility. Hum Reprod 1987;2(6):521 - 33. http://dx.doi.org/10.1093/oxfordjournals.humrep. a136582.

3. Jokela M, Kivimäki M, Elovainio M, Viikari J, Raitakari OT, Keltikangas-Järvinen L. Body mass index in adolescence and number of children in adulthood. Epidemiology 2007;18(5):599 - 606 . http://dx.doi.org/10.1097/ede.0b013e3181257158.

4. Yu DM, Zhao LY, Zhang J, Yang ZY, Yang LC, Huang J, et al. China Nutrition and Health Surveys (1982-2017). China CDC Wkly 2021;3(9):193 - 195. http://dx.doi.org/10.46234/ccdcw2021.058.

5. National Data. Tabulation on the 2010 population census of the People's Republic of China. [2020-1-18]. http://www.stats.gov.cn/ tjsj/pcsj/rkpc/6rp/indexch.htm. (In Chinese).

6. Kronenfeld LW, Reba-Harrelson L, Von Holle A, Reyes ML, Bulik $\mathrm{CM}$. Ethnic and racial differences in body size perception and satisfaction. Body Image 2010;7(2):131 - 6. http://dx.doi.org/10.1016/ j.bodyim.2009.11.002.

7. Lemon SC, Rosal MC, Zapka J, Borg A, Andersen V. Contributions of weight perceptions to weight loss attempts: differences by body mass index and gender. Body Image 2009;6(2):90 - 6. http://dx.doi.org/ 10.1016/j.bodyim.2008.11.004.

8. Bhanji S, Khuwaja AK, Siddiqui F, Azam I, Kazmi K. Underestimation of weight and its associated factors among overweight and obese adults in Pakistan: a cross sectional study. BMC Public Health 2011;11:363. http://dx.doi.org/10.1186/1471-2458-11-363.

9. Duncan DT, Wolin KY, Scharoun-Lee M, Ding EL, Warner ET, Bennett GG. Does perception equal reality? Weight misperception in relation to weight-related attitudes and behaviors among overweight and obese US adults. Int J Behav Nutr Phys Act 2011;8:20. http://dx.doi.org/10.1186/1479-5868-8-20.

10. Liu S, Fu MR, Hu SH, Wang VY, Crupi R, Qiu JM, et al. Accuracy of body weight perception and obesity among Chinese Americans. Obes Res Clin Pract 2016;10 Suppl 1(Suppl 1):S48 - 56. http://dx.doi.org/ 10.1016/j.orcp.2015.04.004.

11. Patel S, Bhopal R, Unwin N, White M, Alberti KG, Yallop J. Mismatch between perceived and actual overweight in diabetic and non-diabetic populations: a comparative study of South Asian and European women. J Epidemiol Community Health 2001;55(5):332 - 3. http://dx.doi.org/ 10.1136/jech.55.5.332. 